Research Article

\title{
Improved Design of a Broadband Dielectric Resonator Antenna with Wide Beam
}

\author{
Yan He (D), Weihua Wang, Hu Yang, and Xiangyu Du \\ College of Electronics Science, National University of Defense Technology, Changsha, Hunan Province, China \\ Correspondence should be addressed to Yan He; 47303832@qq.com
}

Received 26 January 2018; Revised 27 April 2018; Accepted 2 May 2018; Published 11 July 2018

Academic Editor: N. Nasimuddin

Copyright (C) 2018 Yan He et al. This is an open access article distributed under the Creative Commons Attribution License, which permits unrestricted use, distribution, and reproduction in any medium, provided the original work is properly cited.

\begin{abstract}
A wide-beam and broadband dielectric resonator antenna (DRA) with broadside pattern is proposed and analyzed. The excellent performance of wide beam is achieved by designing the metal ground. In addition, the antenna has broad bandwidth by introducing an air gap between the dielectric resonator (DR) and the ground. From simulated results, the impedance bandwidth $\left(\left|S_{11}\right|<-10 \mathrm{~dB}\right)$ of the proposed antenna is about $35 \%$, from 2.8 to $4 \mathrm{GHz}$, and the maximum $3 \mathrm{~dB}$ beam width in $H$-plane is greater than $210^{\circ}$. A prototype of the proposed DRA is produced and tested. Good agreement between the simulated and measured results is achieved.
\end{abstract}

\section{Introduction}

In modern wireless communication systems, such as safeguard systems, active phased arrays, and intelligent transport systems, beam width of the antenna is a significant performance. For example, in communication base station, wide-beam antenna can help to reduce the number of the antenna array to synthesize omnidirectional radiation. In detection system, wide-beam width antenna will increase the coverage area and reduce detection time. Recently, a lot of work has been done to improve the beam width of the antenna. The dipole antenna with the back cavity is useful to get wide-beam characteristic $[1,2]$. However, the size is not easy to be compact. Beyond that, the patch antenna is another alternative. In [3], a low profile patch is proposed with wide-beam performance. However, at the same time, it is difficult to get broadband characteristics for this type of antennas.

Dielectric resonator antenna (DRA) has got more and more attentions for many superiorities compared with metal microstrip antennas such as low conductor loss, high radiation efficiency, and compact size [4]. Much useful work has been done to improve the performance of DRAs, such as wide band [5], multipolarization [6], and high gains [7]. However, there are only a few studies on the wide beam of
DRA in the published literature $[8,9]$, and in these papers, except for the good performance of the beam width, other performances such as impedance bandwidth and the size of the antenna are unsatisfactory. In [10], a wide-band widebeam DRA is proposed by me. However, there are only preliminary simulation results in the paper, no physical test results, design principles, and performance analysis in it.

In this paper, a wide-beam and broadband DRA is proposed. It has a broadside radiation pattern. By comparing the proposed antenna and the previous works in Table 1, the proposed antenna has improved performance.

\section{Antenna Configuration and Design Process}

In Figures 1 and 2, the geometry and the fabricated prototype of the proposed antenna are shown, respectively. The proposed antenna consists of a rectangular DR and a decreased metal ground. A SMA probe is used to excite $\mathrm{TE}_{\delta 11}$ mode in the DR. By optimizing the length and diameter of the probe, impedance matching of the port has been realized. The DR is made of a ceramic material with the dielectric constant $\varepsilon_{\mathrm{r}}=10$. The metal ground is under the DR, and the size is close to the bottom of it. All the configuration parameters for the proposed antenna are presented in Figure 1. 
TABLE 1: Comparisons of different wide-beam antennas.

\begin{tabular}{lccr}
\hline Antenna structures & $\left|S_{11}\right|$ BW $(\%)$ & Maximum 3 dB beam width & Size $\left(\lambda_{0}^{3}\right)$ \\
\hline Proposed antenna & 35 & $214^{\circ}$ & $0.42 \times 0.18 \times 0.16$ \\
Reference [1] (metal antenna) & 22.4 & $185^{\circ}$ & $0.61 \times 0.61 \times 0.22$ \\
Reference [2] (metal antenna) & 33 & $136^{\circ}$ & $0.89 \times 0.89 \times 0.32$ \\
Reference [3] (metal antenna) & 59 & $165^{\circ}$ & $0.64 \times 0.64 \times 0.16$ \\
Reference [8] (DRA) & 4 & $180^{\circ}$ & $0.32 \times 0.31 \times 0.03$ \\
Reference [9] (DRA) & 10 & $86^{\circ}$ & $3 \times 3 \times 0.25$ \\
\end{tabular}

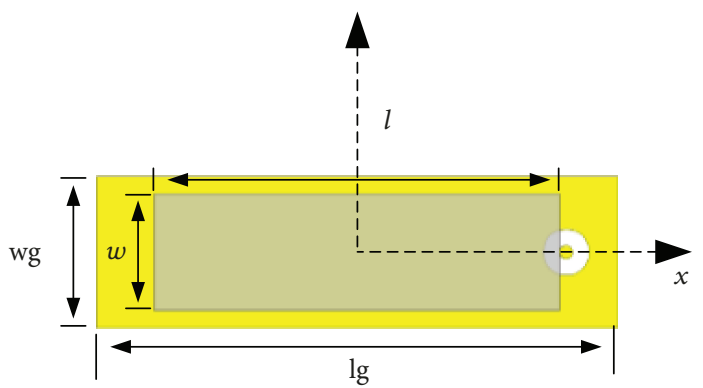

(a)

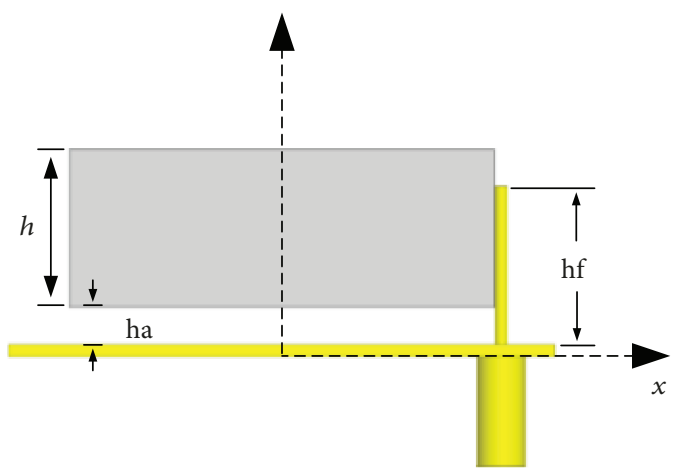

(b)

Figure 1: The configuration of the proposed antenna. (a) Top view (lg $=45 \mathrm{~mm}$, wg $=13 \mathrm{~mm}, l=35 \mathrm{~mm}$, and $w=10 \mathrm{~mm}$ ). (b) Front view $(h=13 \mathrm{~mm}$, ha $=1.5 \mathrm{~mm}$, and $\mathrm{hf}=13 \mathrm{~mm})$.

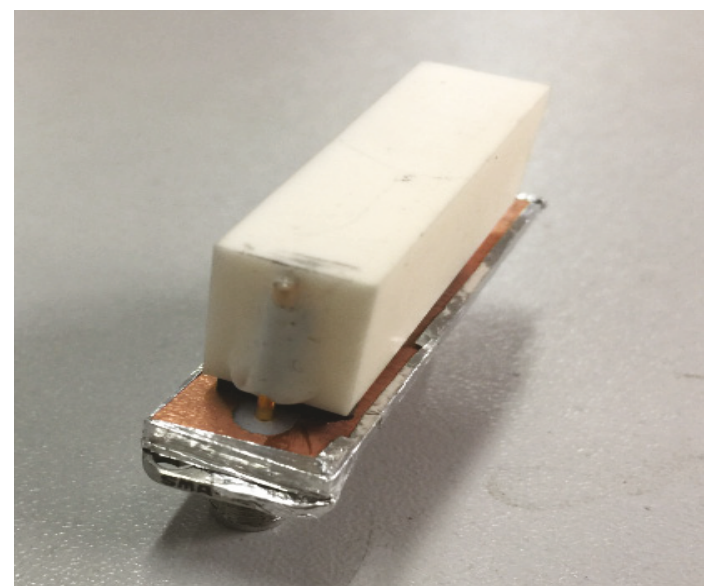

FIGURE 2: Fabricated prototype of the proposed antenna.

The design process of the proposed antenna includes three steps to realize broadband and broadbeam characteristics. First, a rectangular DR with $\varepsilon_{\mathrm{r} 1}=10$ is placed on a big ground, which works in $\mathrm{TE}_{\delta 11}$ mode, as ant.1 shown in Figure 3(a). The resonant frequency of $\mathrm{TE}_{\delta 11}$ mode can be estimated using (1), where $l, w$, and $h$ are length, width, and height of DR, respectively [11], so the size of DR can be approximately calculated. Second, the metal ground is decreased to widen the radiation beam on $H$-plane, as ant. 2 shown in Figure 3(b). The principle will be analyzed in detail in Section 3 of this paper. Finally, an air gap is inserted between the bottom of the DR and the ground to decrease the value of $Q$, which can achieve wide-band feature [12]. The proposed antenna is shown in Figure 3(c). The numerical analysis of the proposed antenna is performed using the commercial 3D full-wave electromagnetic (EM) simulation software Ansoft HFSS, based on the finite element method.

$$
f_{0}=\frac{c}{2 \pi \sqrt{\varepsilon_{\mathrm{r}}}} \sqrt{\left(\frac{m \pi}{l}\right)^{2}+\left(\frac{s+\delta}{w} \pi\right)^{2}+\left(\frac{n \pi}{h}\right)^{2}} .
$$

\section{Analysis and Discussion}

Figure 4 shows the simulated reflection coefficient of two reference and proposed antennas. It can be seen that the reference antenna 1 has two resonant frequencies, which are $3.2 \mathrm{GHz}$ and $4.5 \mathrm{GHz}$, respectively. The first resonant frequency corresponds to $\mathrm{TE}_{\delta 11}$ mode, which has broadside radiation characteristic. However, the bandwidth does not meet the broadband requirement. What is more, decreased metal ground in reference antenna 2 makes the reflection coefficient further deteriorate. In order to increase the bandwidth, an optimized air-filled gap is inserted between the dielectric resonator and the metal ground, which can decrease the value of $Q$ of the DRA and broaden the bandwidth. This is the final proposed antenna. It can be seen that the proposed antenna achieves good impedance matching in a wide band, with the $-10 \mathrm{~dB}$ impedance bandwidth being $2.8-4 \mathrm{GHz}$ and the relative bandwidth achieving $35 \%$. 


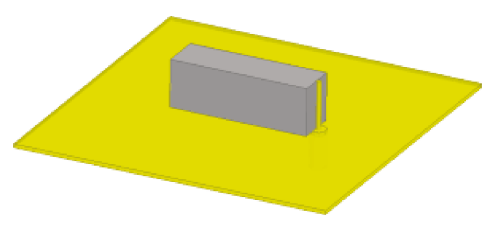

(a)

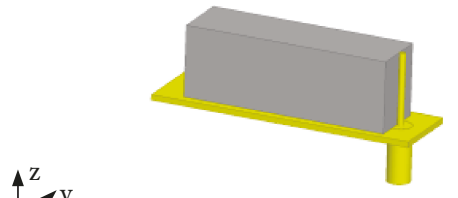

(b)

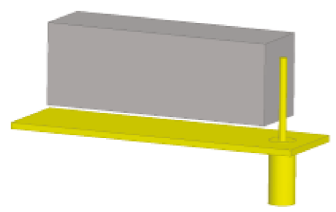

(c)

FIGURE 3: Geometry of the reference and proposed antennas: (a) ant. 1, (b) ant. 2, and (c) proposed antenna.

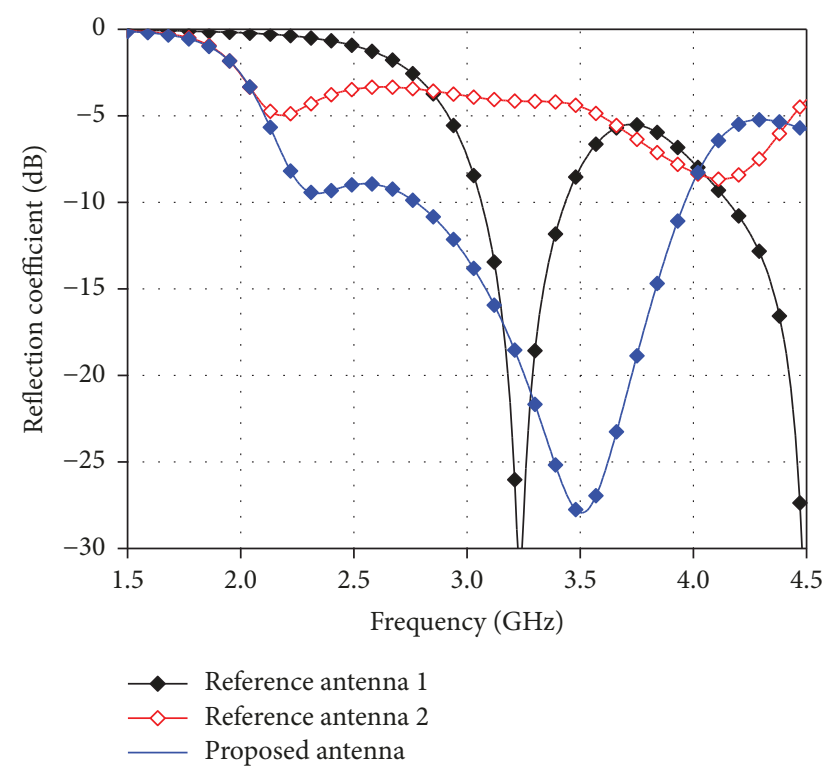

FIGURE 4: Simulated reflection coefficient of two reference and proposed antennas.

In Figure 5, the simulated electric field vector of $\mathrm{TE}_{\delta 11}$ mode on XOZ plane of the proposed antenna at $3.5 \mathrm{GHz}$ is shown. It can be seen that the electric field vector of $\mathrm{TE}_{\delta 11}$ is similar to a horizontal magnetic dipole, in view of the mirror effect of the mental ground, so it has the broadside radiation pattern.

The wide-beam feature of the proposed antenna is achieved by decreasing the metal ground. In Figure 6(a), simulated current field distribution on metal ground of ant. 1 at $3.2 \mathrm{GHz}$ is presented. From it, the current on the ground is along the $y$-axis, and current distribution of the antenna 1 is relatively uniform. The current intensity on the two edges parallel to the $y$-axis is relatively large, while it is very small parallel to the $x$-axis. Therefore, the change of ground size in $Y$ direction has little influence on the current on the ground and the radiation pattern of the DRA. Figure $6(\mathrm{~b})$ shows the simulated current field distribution on metal ground of the proposed antenna at $3.5 \mathrm{GHz}$. In this figure, the ground size is reduced in the $X$ direction. The current intensity increases sharply on the two edges; therefore, the radiation intensity of the current increases. The radiation energy will leak below the metal ground along the edge parallel to the $y$-axis, so the beam width of the antenna on the $\mathrm{XOZ}$ plane ( $\mathrm{H}$-plane) is broadened.

The ground effect on the beam can also be reflected in another picture. Figures 7(a) and Figures 7(b) show the simulated electric field energy distributions on $H$-plane at $3.5 \mathrm{GHz}$ of ant. 1 and the proposed antenna, respectively. The electric field energy of the antenna 1 on $H$-plane is mostly concentrated above the dielectric resonator and has less distribution at the edges and back of the metal ground. When the width of the metal ground is reduced, the back radiation of the antenna is significantly enhanced and the electric field distribution in the space is more uniform. Therefore, the width of the antenna can be effectively broadened by reducing the size of the metal ground.

Figure 8 presents the simulated radiation patterns on $H$-plane with different values of wg. It is evident that the width of metal ground plays a crucial role in the farfield radiation patterns. When $\mathrm{wg}=13 \mathrm{~mm}$, the beam on the $H$-plane is widened obviously. The simulated radiation patterns on $E$-plane with different values of wg are shown in Figure 9; it can be seen that the value of wg has little effect on the width of the $E$-plane beam.

Figure 10 presents the reflection coefficient of the proposed antenna with different values of wg. It is shown that as $\mathrm{wg}$ increases from $13 \mathrm{~mm}$ to $33 \mathrm{~mm}$, the operating band is almost no change. For maximum beam width, $\mathrm{wg}=13 \mathrm{~m}$ $\mathrm{m}$ is the best choice.

In Figure 11, simulated radiation patterns on the $H$-plane with different frequencies of the proposed antenna are shown. When the frequency is $2.8 \mathrm{GHz}$, the $3 \mathrm{~dB}$ beam width is about $214^{\circ}$. When the frequency is increased to $4.0 \mathrm{GHz}$, the $3 \mathrm{~dB}$ beam width is about $140^{\circ}$. Therefore, the beam width of the proposed antenna within the impedance bandwidth is from $140^{\circ}$ to $214^{\circ}$.

Figure 12 shows the simulated curve of front-to-back ratio versus wg at $3.5 \mathrm{GHz}$. It can be seen that front-to-back ratio increases first and then decreases when wg increases. When $\mathrm{wg}=23 \mathrm{~mm}$, the value of front-to-back ratio reaches the maximum of $34 \mathrm{~dB}$. When $\mathrm{wg}=13 \mathrm{~mm}$, the value of front-to-back ratio is about $20 \mathrm{~dB}$. 

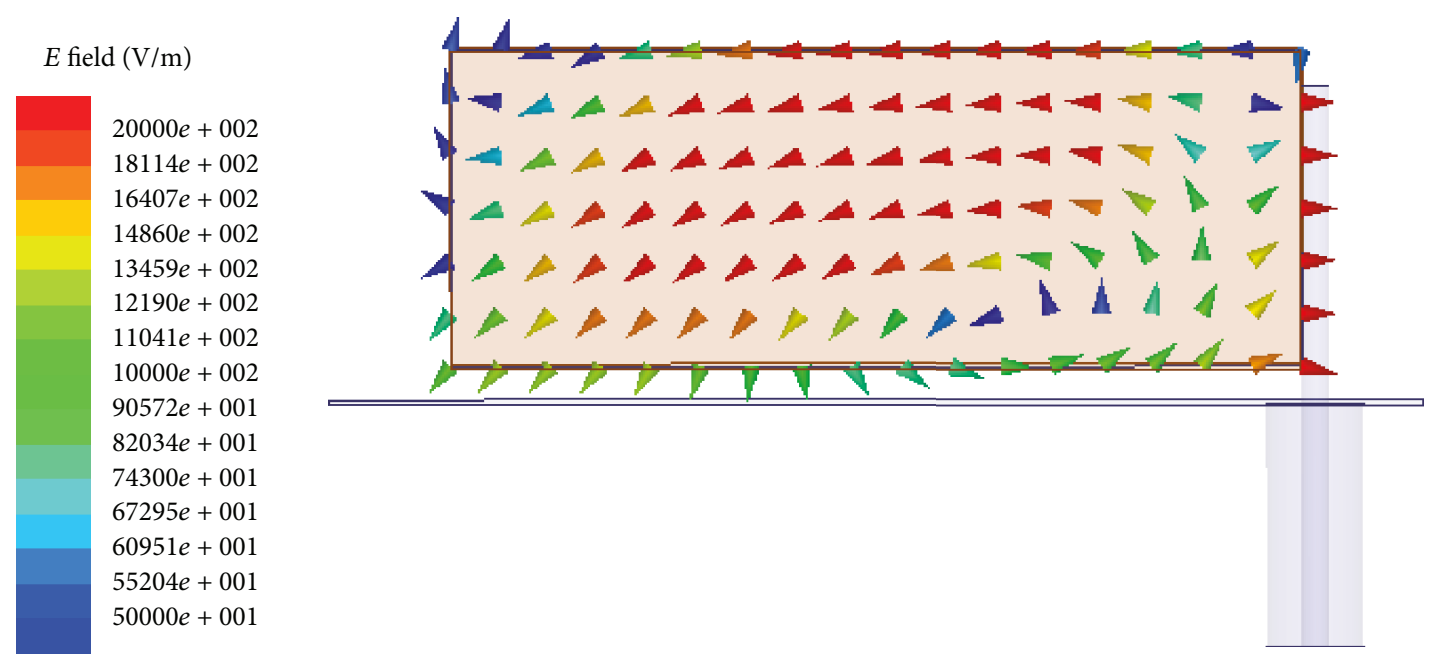

FIGURE 5: Simulated electric field vector of $\mathrm{TE}_{\delta 11}$ mode on $\mathrm{XOZ}$ plane of the proposed antenna.

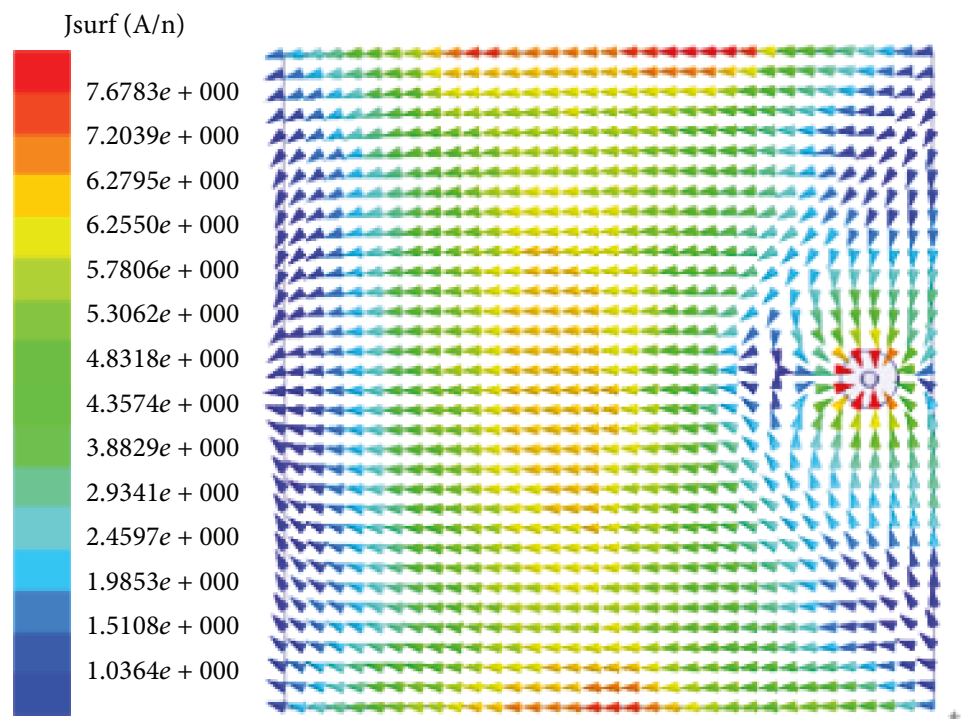

(a)

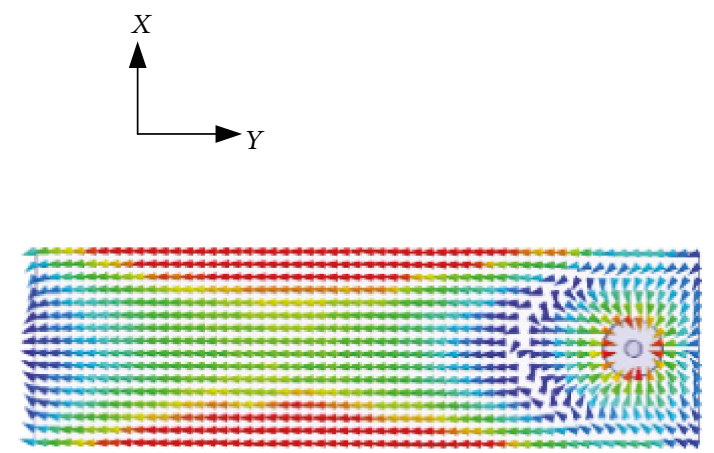

(b)

FIgURE 6: Simulated current field distributions on metal ground: (a) ant. 1 and (b) proposed antenna.

Figure 13 presents the simulated gain versus wg at 3.5 GHz. As can be seen from it, the gain gradually increases as the value of $\mathrm{wg}$ increases. By comparing the results of Figure 8, we can draw a conclusion that when the beam width of $H$-plane increases, the gain reduces, because the energy distribution is not concentrated.

\section{Experimental Results and Discussions}

To prove the theoretical analysis, the proposed antenna has been fabricated. It was measured by Agilent N5242A vector network analyzer. In Figure 14, the measured and simulated reflection coefficient of the proposed antenna is shown. It can be seen that the measured curve of $\left|S_{11}\right|$ is very close to the simulated one, covering the frequency range from 2.8 to
$4 \mathrm{GHz}\left(\left|S_{11}\right|<-10 \mathrm{~dB}\right)$, indicating a relative impedance bandwidth of $35 \%$.

The proposed wide-band wide-beam DRA has also been measured in an anechoic chamber. Figure 15 shows far-field radiation patterns (both copolar and cross-polar) at $3.5 \mathrm{GHz}$ on the $E$-plane (XOZ plane) and $H$-plane (YOZ plane). From that, the $3 \mathrm{~dB}$ beam width on $H$-plane of the proposed antenna is greater than $180^{\circ}$ at $3.5 \mathrm{GHz}$. The measured crosspolarization levels in the maximum radiation direction achieve $-20 \mathrm{~dB}$ and $-35 \mathrm{~dB}$ on the $H$-plane and $E$-plane, respectively.

In Figure 16, simulated gain and measured gain versus frequency of the proposed antenna are illustrated. It can be seen that the measured gain shows a good agreement with the simulated one. The maximum measured gain reaches $5.1 \mathrm{~dB}$. 
$\backslash$

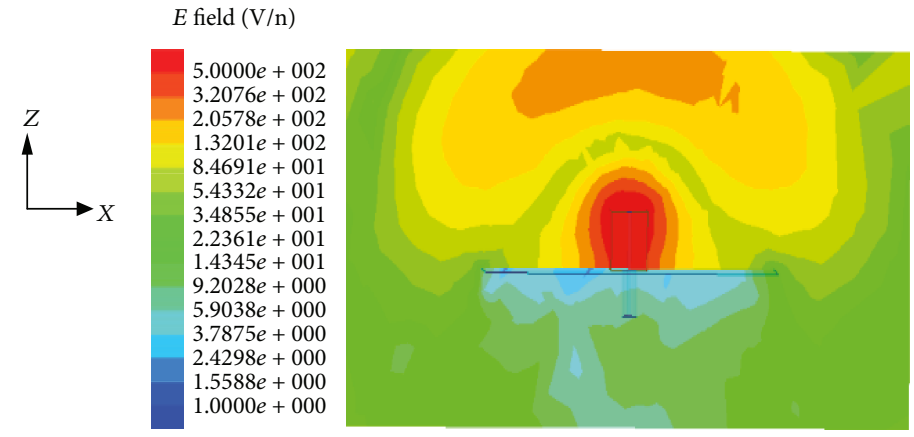

(a)

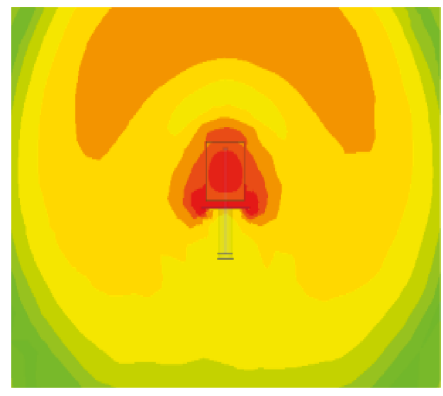

(b)

Figure 7: Simulated electric field energy distribution on $H$-plane: (a) ant. 1 and (b) proposed antenna.

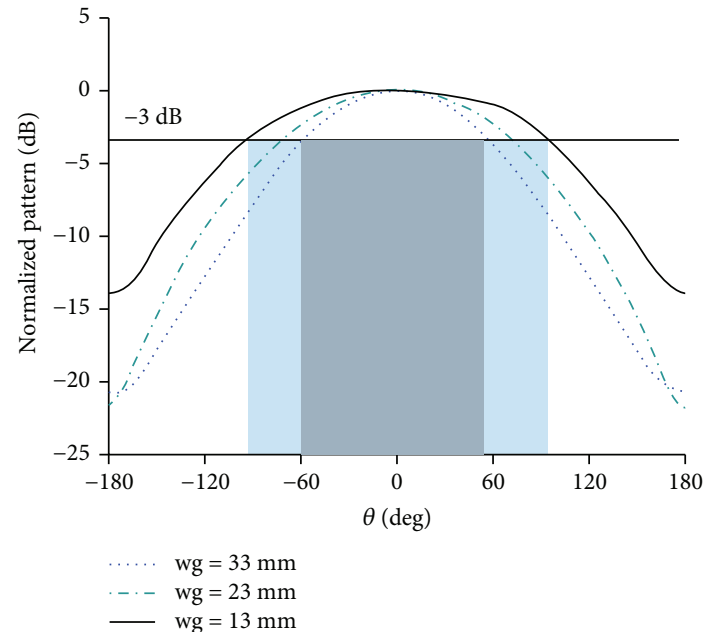

FIGURE 8: Simulated radiation patterns on the $H$-plane with different values of wg.

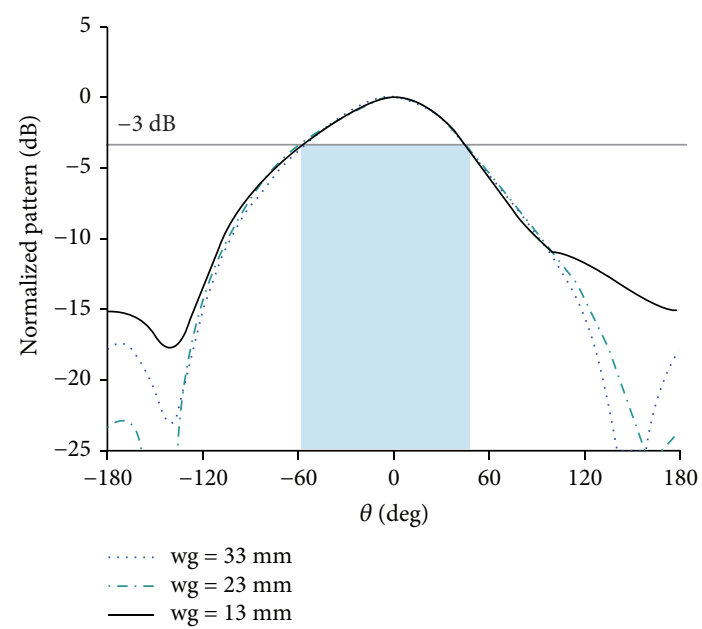

FIGURE 9: Simulated radiation patterns on the $H$-plane with different values of wg.

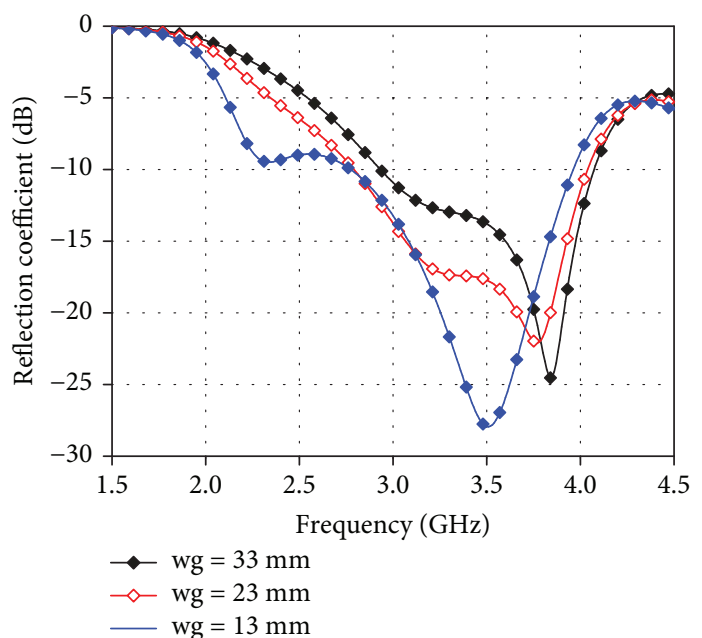

FIgURE 10: Simulated reflection coefficient of the proposed antenna with different values of wg.

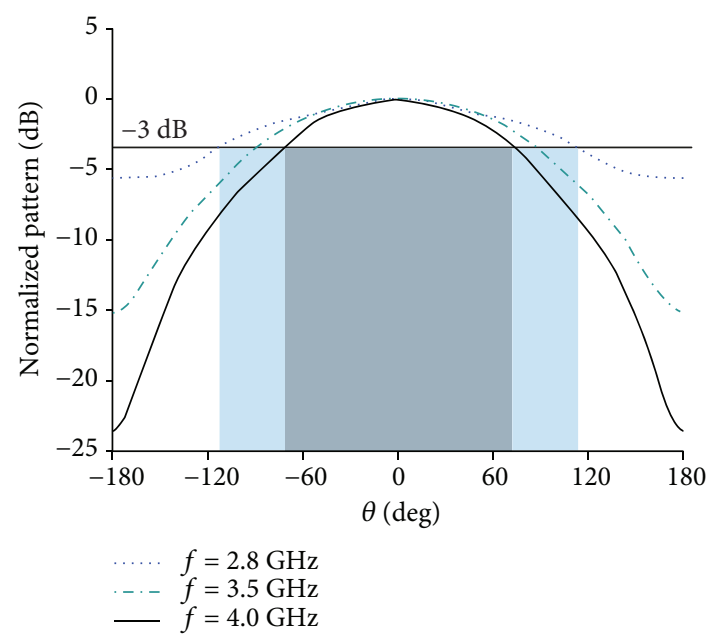

FIgURE 11: Simulated radiation patterns on the $H$-plane with different frequencies of the proposed antenna. 


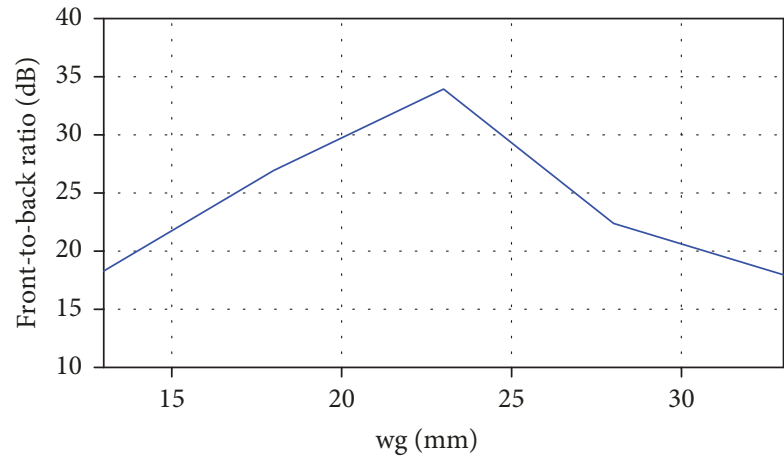

FiguRE 12: Simulated curve of front-to-back ratio versus wg at $3.5 \mathrm{GHz}$.

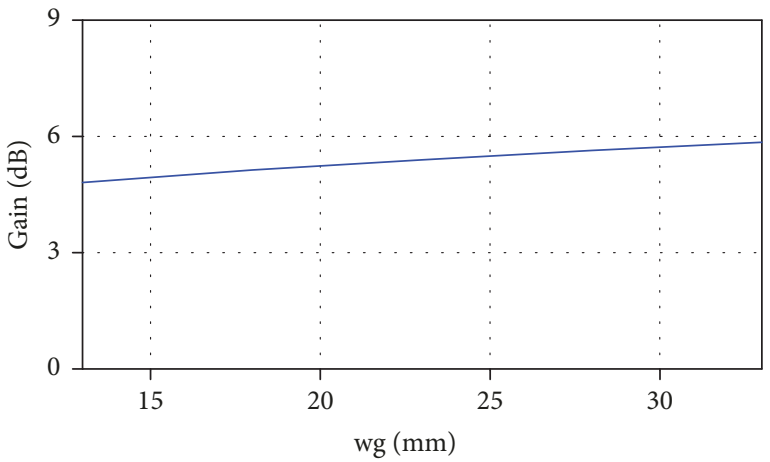

Figure 13: Simulated curve of gain versus wg at $3.5 \mathrm{GHz}$.

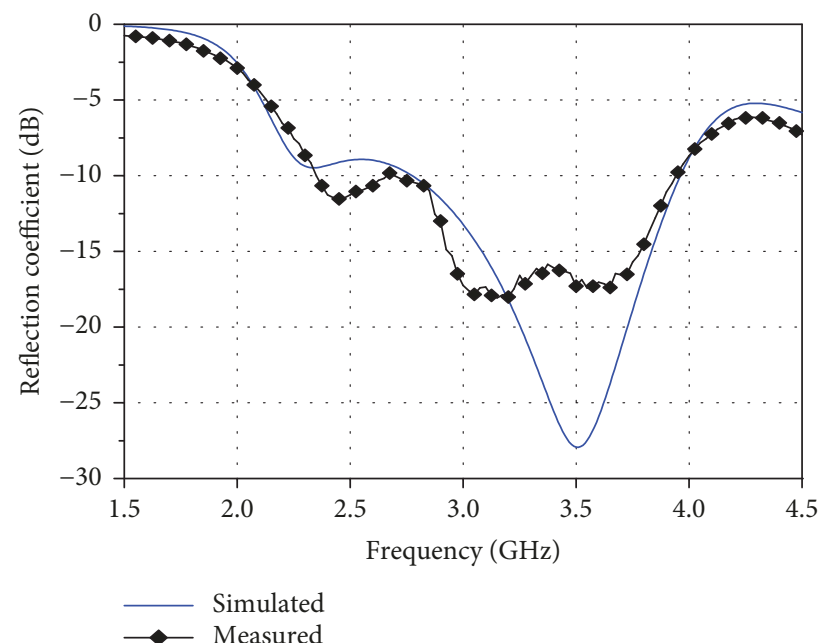

FIGURE 14: Measured and simulated reflection coefficient of the proposed antenna.

The partial parameters are presented in Table 1. It can be seen that the proposed antenna has better comprehensive performance compared with others.

\section{Conclusion}

A wide-band wide-beam dielectric resonator antenna has been developed in this paper. Its measured impedance
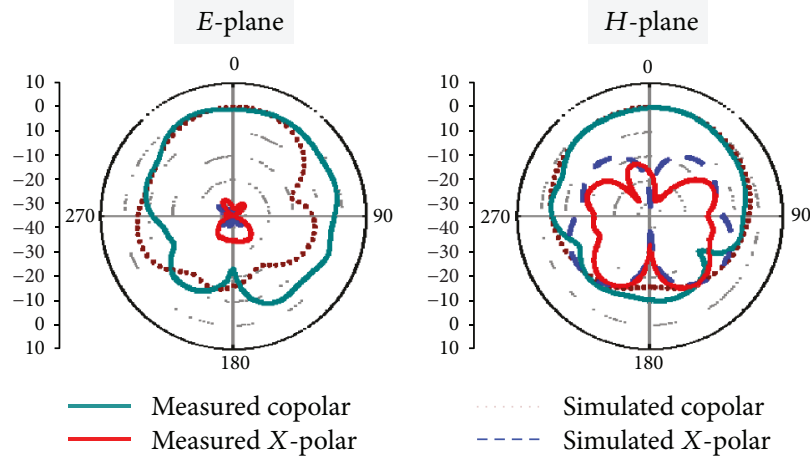

Simulated copolar Simulated $X$-polar

Figure 15: Measured and simulated radiation patterns of the proposed antenna in $E$-plane (a) and $H$-plane (b) at $f=3.5 \mathrm{GHz}$.

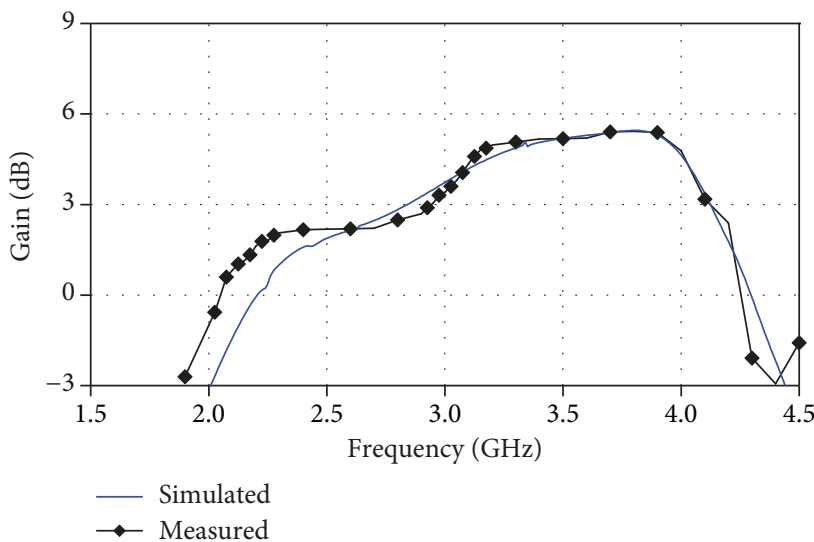

Figure 16: Simulated and measured gains versus frequency of the proposed antenna.

bandwidth $\left(\left|S_{11}\right|<-10 \mathrm{~dB}\right)$ is from $2.8 \mathrm{~Hz}$ to $4 \mathrm{GHz}$, which is about $35 \%$. Furthermore, wide-beam characteristic on the $H$-plane (XOY plane) is obtained. It may be serviceable in wireless communication systems which seek wide-band and wide-beam radiation features.

\section{Data Availability}

The data used to support the findings of this study are available from the corresponding author upon request.

\section{Conflicts of Interest}

The authors declare that they have no conflicts of interest.

\section{References}

[1] K. Saurav, D. Sarkar, and K. V. Srivastava, "Dual-band circularly polarized cavity-backed crossed-dipole antennas," IEEE Antennas and Wireless Propagation Letters, vol. 14, pp. 52-55, 2015.

[2] S. X. Ta and I. Park, "Crossed dipole loaded with magnetoelectric dipole for wideband and wide-beam circularly polarized radiation," IEEE Antennas and Wireless Propagation Letters, vol. 14, pp. 358-361, 2015. 
[3] C. Liu, S. Xiao, and Z. Zhang, "A low profile linearly polarized patch antenna with wide beam-width in E-plane," in 2016 IEEE International Workshop on Electromagnetics: Applications and Student Innovation Competition (iWEM), pp. 1-3, Nanjing, China, May 2016.

[4] K. W. Leung, E. H. Lim, and X. S. Fang, "Dielectric resonator antennas: from the basic to the aesthetic," Proceedings of the IEEE, vol. 100, no. 7, pp. 2181-2193, 2012.

[5] Y. He, Y. Lin, C. Deng, and Z. Feng, "Annular column loaded cylindrical dielectric resonator antenna for wideband conical radiation," IEEE Transactions on Antennas and Propagation, vol. 63, no. 12, pp. 5874-5878, 2015.

[6] R.-Y. Sun and R.-C. Han, "Design of dual-polarized differential feed dielectric resonator antenna," in 2015 IEEE MTT-S International Microwave Workshop Series on Advanced Materials and Processes for RF and THz Applications (IMWS-AMP), pp. 1-3, Suzhou, China, July 2015.

[7] G. Yang, F. Zhenghe, and Z. Li, "High-gain silicon based on-chip dielectric resonator antenna at 60GHz," in 2012 International Conference on Microwave and Millimeter Wave Technology (ICMMT), vol. 1, pp. 1-4, Shenzhen, China, May 2012.

[8] D. Y. Kim, C. S. Kim, D. M. Kang, and J. W. Lim, "Substrate embedded low temperature co-fired ceramics antenna with wide beamwidth and high gain at millimetre-wave band," Electronics Letters, vol. 52, no. 2, pp. 98-100, 2016.

[9] D. Guha, P. Gupta, and C. Kumar, "New mode in dielectric resonator antenna with strawberry shaped radiations covering a wide beamwidth," in 2013 IEEE Antennas and Propagation Society International Symposium (APSURSI), pp. 1912-1913, Orlando, FL, USA, July 2013.

[10] Y. He, W. Wang, and D. Xiangyu, "A wide-band wide-beam dielectric resonator antenna," in 2017 IEEE Conference on Antenna Measurements \& Applications (CAMA), pp. 210212, Tsukuba, Japan, December 2017.

[11] A. Petosa, Dielectric Resonator Antenna Handbook, Artech House, Boston, 2007.

[12] M. Ranjbar Nikkhah, J. Rashed-Mohassel, and A. A. Kishk, "Compact wideband rectangular dielectric resonator antenna with parasitic elements and air gaps," Progress in Electromagnetics Research Letters, vol. 42, pp. 129-139, 2013. 


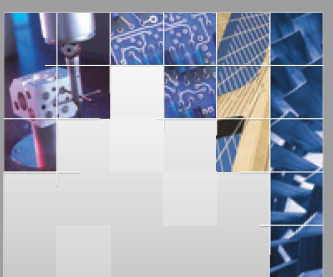

\section{Enfincering}
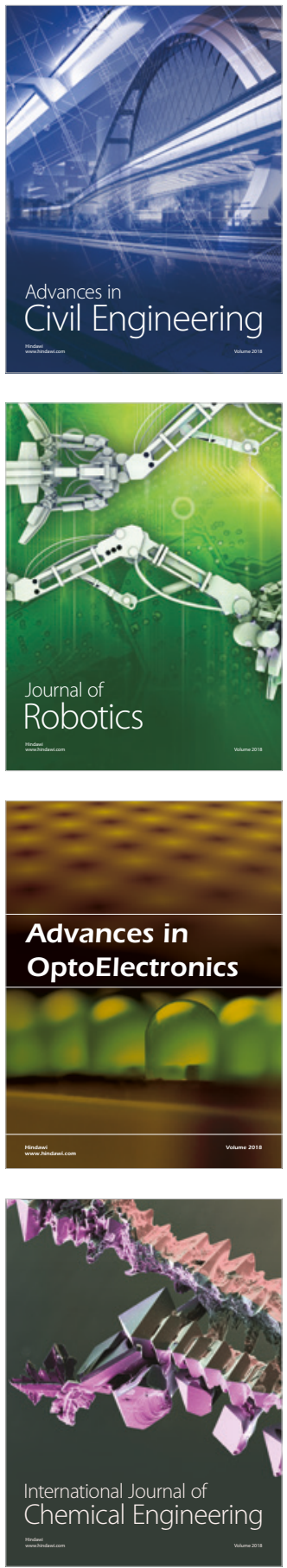

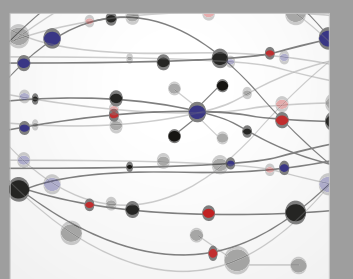

\section{Rotating \\ Machinery}

The Scientific World Journal

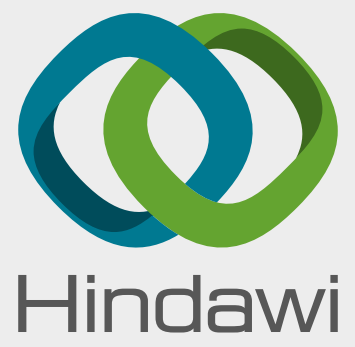

Submit your manuscripts at

www.hindawi.com
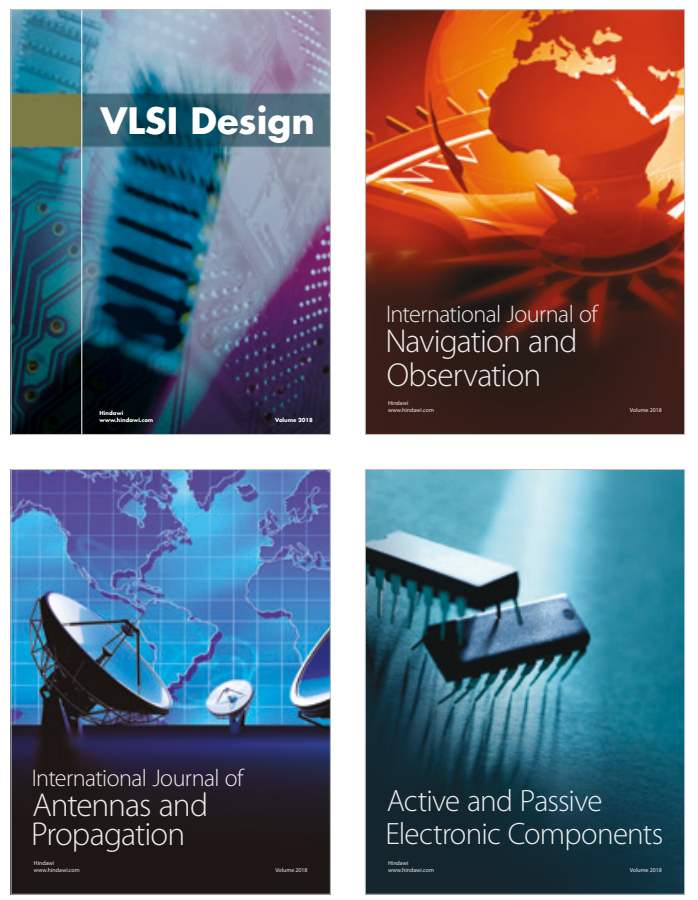
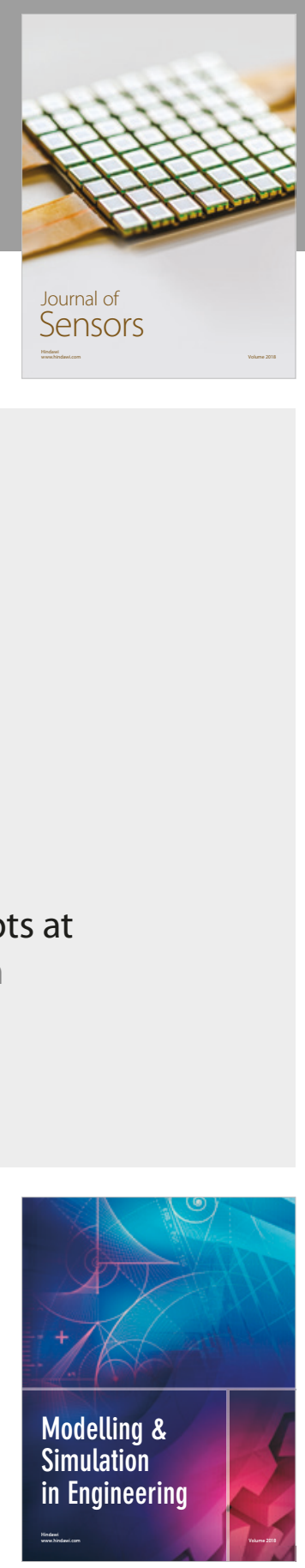

\section{Advances \\ Multimedia}
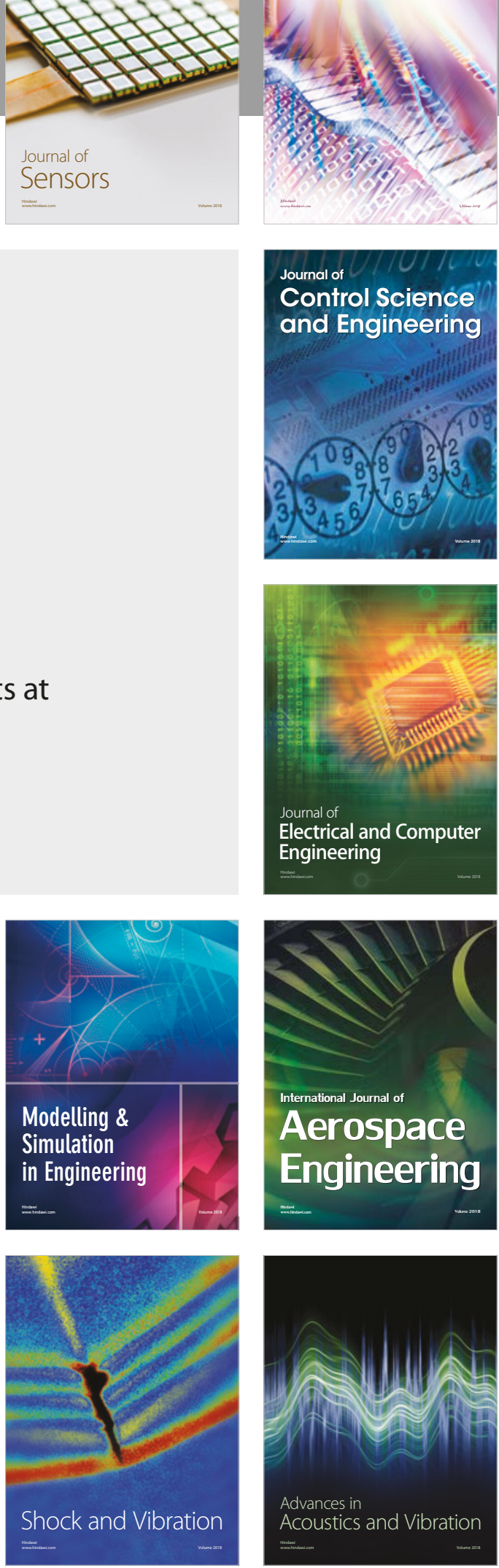